\title{
Ferric carboxymaltose vs. oral iron in the treatment of pregnant women with iron deficiency anemia: an international, open-label, randomized controlled trial (FER-ASAP)
}

DOI 10.1515/jpm-2016-0050

Received February 15, 2016. Accepted April 18, 2016. Previously published online June 8, 2016.

\section{Abstract}

Objective: To compare the efficacy and safety of intravenous ferric carboxymaltose (FCM) with first-line oral ferrous sulfate (FS) in pregnant women with iron deficiency anemia (IDA).

Materials and methods: Pregnant women ( $\mathrm{n}=252$; gestational weeks 16-33) with IDA were randomized 1:1 to FCM (1000-1500 mg iron) or FS (200 mg iron/day) for 12 weeks. The primary objective was to compare efficacy; secondary objectives included safety and quality of life.

Results: Hemoglobin $(\mathrm{Hb})$ levels improved at comparable rates across both treatments; however, significantly more women achieved anemia correction with FCM vs. FS $[\mathrm{Hb} \geq 11.0 \mathrm{~g} / \mathrm{dL} ; 84 \%$ vs. $70 \%$; odds ratio (OR): $2.06,95 \%$ confidence interval (CI): 1.07, 3.97; $\mathrm{P}=0.031]$ and within a shorter time frame (median 3.4 vs. 4.3 weeks). FCM treatment significantly improved vitality $(\mathrm{P}=0.025)$ and social functioning $(\mathrm{P}=0.049)$ prior to delivery. Treatmentrelated adverse events were experienced by 14 (FCM; 11\%) and 19 (FS; 15\%) women, with markedly higher rates of

*Corresponding author: Christian Breymann, MD, Clinic of Obstetrics, Obstetric Research and Feto-Maternal Haematology Unit, University Hospital Zürich, Frauenklinikstrasse 10, CH-8091 Zürich, Switzerland, Tel.: +411255 1111/5134, Fax: +411255 4430, E-mail: christian.breymann@usz.ch Nils Milman: Departments of Clinical Biochemistry and Obstetrics, Næstved Hospital, University of Copenhagen, Næstved, Denmark Anna Mezzacasa: Global Medical Affairs Director Women's Health, Patient Blood Management and Life Cycle Management, Vifor Pharma, Glattbrugg, Switzerland

Roubert Bernard: Vifor Pharma, Glattbrugg, Switzerland Joachim Dudenhausen: Department of Obstetrics, Charité Universitätsmedizin Berlin, Berlin, Germany gastrointestinal disorders reported with FS (16 women) than with FCM (3 women). Newborn characteristics were similar across treatments.

Conclusions: During late-stage pregnancy, FCM may be a more appropriate option than first-line oral iron for rapid and effective anemia correction, with additional benefits for vitality and social functioning.

Keywords: Clinical trial; ferric carboxymaltose; hemoglobin; intravenous; iron deficiency anemia; newborn; pregnancy; quality of life; serum ferritin.

\section{Introduction}

Pregnancy significantly increases the need for iron; the dramatic physiological changes of the mother and the increasing demands of the growing fetus lead to major maternal hematological changes, of which increased red blood cell mass and, in the third trimester, expansion of blood volume are key [1-3]. This increased demand for iron subsequently places the mother and infant at risk of developing iron deficiency anemia (IDA), which can lead to gestational complications, as well as increased maternal and infant morbidity and mortality [4-7]. This risk is a global phenomenon and the prevalence of anemia in pregnant women is high, affecting $41.8 \%$ of all pregnant women worldwide [8]. Such high prevalence indicates that, by and large, dietary uptake of iron is insufficient to meet physiological demands during pregnancy [3], and effective management of IDA in pregnancy is currently lacking.

Oral iron is routinely used to treat IDA in pregnant women. However, this can often lead to gastrointestinal side effects, such as nausea, diarrhea or vomiting, that impact on the adherence to and, ultimately, the efficacy of the iron treatment $[5,9,10]$. In those women who do 
not respond to, are non-compliant with, or are unable to tolerate oral iron treatment, intravenous (IV) iron preparations may provide a better option [9-11]. As such, IV iron preparations are increasingly being recommended for women with severe IDA and when IDA is diagnosed later in pregnancy and rapid intervention is required $[9,11$, 12]. IV preparations can deliver a larger iron supply more rapidly than oral iron and, because of the route of administration, bypass the risk of gastrointestinal side effects. However, among currently available IV iron preparations, some require multiple doses [5], some require long infusion times, while others have very little data published on proven clinical benefit versus risks.

Ferric carboxymaltose (FCM; Ferinject ${ }^{\circledR}$ ) is a dextranfree IV iron preparation that allows rapid administration of high single doses of iron (up to $1000 \mathrm{mg}$ iron in $15 \mathrm{~min}$ ) once a week. FER-ASAP (FERric carboxymaltose - Assessment of SAfety and efficacy in Pregnancy) was the first randomized, controlled trial to assess FCM in pregnant women with IDA.

\section{Methods}

\section{Participants}

Pregnant women aged $\geq 18$ years, in their second or third trimester (gestational weeks 16-33) and with serum ferritin levels $\leq 20 \mathrm{ng} / \mathrm{mL}$ and IDA [defined as hemoglobin ( $\mathrm{Hb})$ 8.0-10.4 g/dL for gestation weeks 16-26 or $\mathrm{Hb} \leq 11.0 \mathrm{~g} / \mathrm{dL}$ for gestation weeks 27-33] were eligible for this study. Women were excluded if they had a significant bleed or surgery within 3 months prior to screening, received a blood transfusion, erythropoietin treatment, oral iron (unless the dose was $\leq 100 \mathrm{mg}$ iron per day) or parenteral iron treatment during the month prior to screening, or were anticipated to need a blood transfusion during the study period. Other exclusion criteria included anemia that was not caused by iron deficiency (ID) or was related to other acute or ongoing disorders, multiple pregnancies, fetal abnormalities evident on ultrasound, or any serious medical condition that may prevent completion of the trial.

\section{Study design}

FER-ASAP was an international, Phase IIIb, open-label study in which pregnant women were randomized 1:1 to receive IV FCM (Ferinject ${ }^{\circledR}$; 1000-1500 mg iron) or oral ferrous sulfate (FS; Plastufer ${ }^{\circledR} ; 100 \mathrm{mg}$ capsules taken twice daily; total daily dose $200 \mathrm{mg}$ iron) (ClinicalTrials.gov identifier: NCT01131624). FCM dosing regimens were stratified according to body weight (Table 1) in order not to exceed a dose of $15 \mathrm{mg}$ iron per $\mathrm{kg}$ of body weight per single dose, with all infusions to be completed by week 3. Oral FS was to be taken daily for 12 weeks. This study was conducted in accordance with the principles of the Declaration of Helsinki and Good Clinical Practice guidelines, and institutional review boards or independent ethics committees of all investigational sites approved the protocol. All study participants provided written informed consent prior to enrollment.
Table 1: Ferric carboxymaltose administration schedule.

\begin{tabular}{|c|c|c|}
\hline \multirow{2}{*}{$\begin{array}{l}\text { Baseline } \mathrm{Hb} \\
(\mathrm{g} / \mathrm{dL})\end{array}$} & \multicolumn{2}{|l|}{ Body weight } \\
\hline & $<66 \mathrm{~kg}$ & $\geq 66$ kg \\
\hline $8.0-9.0$ & $\begin{array}{l}3 \times 500 \mathrm{mg} \text { iron within } \\
2 \text { weeks of baseline }\end{array}$ & $\begin{array}{l}1 \times 1000 \mathrm{mg} \text { iron, followed by } \\
1 \times 500 \mathrm{mg} \text { iron } 1 \text { week later }\end{array}$ \\
\hline $9.1-10.5 / 11.0$ & $\begin{array}{l}2 \times 500 \mathrm{mg} \text { iron within } \\
2 \text { weeks of baseline }\end{array}$ & $1 \times 1000 \mathrm{mg}$ iron \\
\hline
\end{tabular}

$\mathrm{Hb}=$ Hemoglobin.

\section{Study objectives and assessments}

The primary objective was to compare the efficacy of IV FCM with oral FS as treatment of IDA in pregnant women during their second and third trimesters. Secondary objectives were to determine the safety and tolerability of FCM in pregnant women and their newborns, and to determine the relationship between iron status and women's quality of life.

Efficacy assessments were performed at baseline, weeks 3, 6, 9, and 12 and/or prior to delivery (whichever came first; samples prior to delivery could be taken at any point after week 3). The primary efficacy endpoint was the change in $\mathrm{Hb}$ from baseline to week 3. Secondary efficacy endpoints were change in $\mathrm{Hb}$ and other serum iron parameters, the proportion of women who achieved anemia correction (defined as $\mathrm{Hb} \geq 11.0 \mathrm{~g} / \mathrm{dL}$ ), and time to anemia correction. Changes in quality of life were also evaluated: the 36-item short-form (SF-36) health survey was completed at baseline, week 3 and prior to delivery. Safety was monitored throughout and comprised the incidence of treatment-emergent adverse events (TEAEs; defined as an adverse event that occurred or increased in severity after the first dose of medication was administered) and treatment-related TEAEs, coded according to the Medical Dictionary for Regulatory Activities (version 16.1). Changes in routine hematological and biochemical laboratory parameters, physical examinations and vital signs were also evaluated at the same time as efficacy assessments. Apgar scores and other newborn parameters were also assessed. Newborns delivered at hospitals that were not participating in this study were not assessed. Blood samples were taken using standard venipuncture techniques and clinical laboratory parameters $[\mathrm{Hb}$, serum ferritin, total iron binding capacity, serum iron, transferrin saturation (TSAT), soluble transferrin receptor] were assessed by an independent laboratory.

\section{Statistical analysis}

A sample size of 120 women per treatment arm was considered sufficiently powered to detect cross-group differences in $\mathrm{Hb}$ levels at week 3 versus baseline ( $\alpha=0.05$, two sided; $90 \%$ power). The sample size was increased to 125 women per treatment arm to account for low expected discontinuation at week 3; therefore, the total planned study population size was 250 .

Efficacy analyses were conducted on the full analysis set (intent to treat), which comprised all randomized women who received at least one dose of study treatment and had at least one efficacy assessment available at baseline and within the study period. The primary 
efficacy endpoint was analyzed using an analysis of covariance (ANCOVA) model with factors for treatment, pooled countries [South Korea, Russia, rest of the world (Australia, Singapore, Sweden, Switzerland and Turkey)] and baseline $\mathrm{Hb}$ level; changes in $\mathrm{Hb}$ and other serum iron parameters at weeks 6,9 , and 12 and delivery were also analyzed using this model. Logistic regression, including the same factors accounted for in the primary efficacy analysis, was used to compare the proportions of women achieving anemia correction, and an unstratified log-rank test was used to explore the time to anemia correction. SF-36 domain scores were calculated using the algorithms provided within the SF-36 documentation and analyzed as for the primary efficacy endpoint. Safety data were summarized descriptively; the safety population comprised all women who received at least one dose of study treatment. Data from newborns were also summarized descriptively. For all analyses, missing data were treated as missing no imputation was performed.

\section{Results}

\section{Patients}

Between November 2010 and May 2014, 252 pregnant women [median age 31 years (range 27-35)] from 29 centers across seven countries were randomized to IV FCM $(n=126)$ or oral FS $(n=126)$ (Figure 1$)$. The majority of participants $(88 \%)$ completed the study, with similar withdrawal rates between the treatment arms (Figure 1). Most withdrawals from the study were because of voluntary discontinuation by the participant (8 women treated with FCM and 6 with FS); one woman treated with FCM

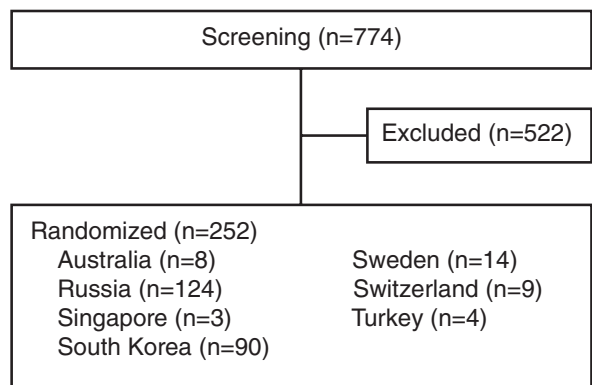

Randomization

\begin{tabular}{|c|c|}
\hline $\begin{array}{l}\text { Randomized to ferric carboxymaltose }(n=126) \\
\text { Received ferric carboxymaltose }(n=123) \\
\text { Did not receive ferric carboxymaltose }(n=3)\end{array}$ & $\begin{array}{l}\text { Randomized to ferrous sulfate }(n=126) \\
\text { Received ferrous sulfate }(n=124) \\
\text { Did not receive ferrous sulfate }(n=2)\end{array}$ \\
\hline & \\
\hline $\begin{array}{l}\text { Completed study }(n=111) \\
\text { Discontinued ferric carboxymaltose by end of } \\
\text { study }(n=15) \\
\text { TEAE }(n=1) \\
\text { Voluntary discontinuation }(n=8) \\
\text { Protocol deviation }(n=1) \\
\text { Lost to follow-up }(n=4) \\
\text { Other }(n=1)\end{array}$ & $\begin{array}{l}\text { Completed study }(n=110) \\
\text { Discontinued ferrous sulfate by end of study } \\
(n=16) \\
\text { TEAE }(n=7) \\
\text { Voluntary discontinuation }(n=6) \\
\text { Protocol deviation }(n=1) \\
\text { Lost to follow-up }(n=2)\end{array}$ \\
\hline \multicolumn{2}{|c|}{ Analysis } \\
\hline $\begin{array}{l}\text { Full analysis set }(n=121) \\
\text { No study medication taken }(n=3) \\
\text { No baseline and evaluable post-baseline } \\
\text { efficacy assessment }(n=2) \\
\text { Safety analysis set }(n=123) \\
\text { No study medication taken }(n=3)\end{array}$ & $\begin{array}{l}\text { Full analysis set }(n=115) \\
\text { No study medication taken }(n=2) \\
\text { No baseline and evaluable post-baseline } \\
\text { efficacy assessment }(n=9) \\
\text { Safety analysis set }(n=124) \\
\text { No study medication taken }(n=2)\end{array}$ \\
\hline
\end{tabular}

Figure 1: Participant disposition.

$T E A E=$ treatment-emergent adverse event. 
and seven treated with FS withdrew because of TEAEs (Figure 1). Participant demographics and baseline characteristics were generally balanced between the treatment arms and were representative of the target population (Table 2). Samples for the time point of last visit prior to delivery were taken a median of 14.5 (range 2-93) days before delivery for the FCM group and 15.0 (range 2-85) days before delivery for the FS group. By week 12, many of the participating women had already given birth; as such, there are limited data for the hematological assessments at this time point.

\section{Efficacy}

$\mathrm{Hb}$ levels improved with both study treatments at each visit throughout the assessment period (Figure 2). Mean changes in $\mathrm{Hb}$ for the FCM group were consistently superior to mean changes in $\mathrm{Hb}$ for FS (change in $\mathrm{Hb}$ at week 3: $1.23 \pm 0.95 \mathrm{~g} / \mathrm{dL}$ vs. $0.96 \pm 1.38 \mathrm{~g} / \mathrm{dL}$, respectively), although statistical significance was not reached at week 3 [least-squares mean: 1.16 vs. 1.04; difference:
0.12, 95\% confidence interval (CI): $-0.10,0.34 ; \mathrm{P}=0.274$; repeated-measures model]; therefore, the primary efficacy endpoint was not met at week 3. However, a statistically significant improvement in mean change in $\mathrm{Hb}$ levels from baseline was achieved for FCM vs. FS at week 6 (change in $\mathrm{Hb}: 1.75 \pm 1.18 \mathrm{~g} / \mathrm{dL}$ vs. $1.32 \pm 1.54 \mathrm{~g} / \mathrm{dL}$; least-squares mean: 1.68 vs. 1.40 ; difference: $0.28,95 \%$ CI: 0.02, 0.55; $\mathrm{P}=0.032$; repeated-measures model). Pregnant women treated with FCM were twice as likely to achieve anemia correction ( $\mathrm{Hb} \geq 11.0 \mathrm{~g} / \mathrm{dL}$ ) than those treated with FS [84\% $(n=101)$ vs. $70 \%(n=80)$; odds ratio (OR): 2.06, 95\% CI: 1.07, 3.97; $\mathrm{P}=0.031$ ], and the median time to achieving this correction was shorter with FCM treatment (3.4 vs. 4.3 weeks).

Comparative analysis of other hematological parameters revealed sustained, significantly greater increases in serum ferritin levels with FCM treatment compared with FS (Figure 3A). Similar TSAT levels between treatment arms were seen up to the week 9 assessment; however, at week 12 and prior to delivery, TSAT levels were significantly greater with FS treatment (Figure 3B). Soluble transferrin receptor levels decreased with both treatments, with

Table 2: Participant demographics and baseline characteristics (safety analysis set).

\begin{tabular}{|c|c|c|}
\hline & $\begin{array}{r}\text { Ferric carboxymaltose } \\
\qquad(n=123)\end{array}$ & $\begin{array}{r}\text { Ferrous sulfate } \\
(n=124)\end{array}$ \\
\hline Age, median (range), years & $31(18-44)$ & $31(19-52)$ \\
\hline \multicolumn{3}{|l|}{ Age category, n (\%) } \\
\hline$<36$ years & $91(74)$ & $100(81)$ \\
\hline$\geq 36$ years & $32(26)$ & 24 (19) \\
\hline \multicolumn{3}{|l|}{ Race, n (\%) } \\
\hline White & $73(59)$ & $76(61)$ \\
\hline Black/African American & $1(1)$ & $3(2)$ \\
\hline Asian & $47(38)$ & $45(36)$ \\
\hline Other & $2(2)$ & $0(0)$ \\
\hline Pre-pregnancy weight, mean (SD), kg & $59.3(11.6)$ & $57.4(10.7)$ \\
\hline Pre-pregnancy BMI, mean (SD), kg/m² & $22.1(3.7)$ & $21.6(3.5)$ \\
\hline Baseline weight, mean (SD), kg & $66.9(12.4)$ & $65.5(11.2)$ \\
\hline \multicolumn{3}{|l|}{ Baseline weight category, n (\%) } \\
\hline$<66 \mathrm{~kg}$ & $69(56)$ & $68(55)$ \\
\hline$\geq 66$ kg & $54(44)$ & $56(45)$ \\
\hline Baseline $\mathrm{Hb}$ level, mean (SD), g/L & $98(0.8)$ & $99(1.2)$ \\
\hline \multicolumn{3}{|l|}{ Baseline $\mathrm{Hb}$ level category, n (\%) } \\
\hline$\leq 9.0 \mathrm{~g} / \mathrm{dL}$ & $22(18)$ & $17(14)$ \\
\hline$>9.0 \mathrm{~g} / \mathrm{dL}$ & $101(82)$ & $106(86)$ \\
\hline Baseline serum ferritin level, mean (SD), $\mathrm{ng} / \mathrm{mL}$ & $12.15(35.3)$ & $12.35(32.0)$ \\
\hline \multicolumn{3}{|l|}{ Gestational age category, $\mathrm{n}(\%)$} \\
\hline$<16$ weeks & $0(0)$ & $0(0)$ \\
\hline $16-<20$ weeks & $12(10)$ & $9(7)$ \\
\hline $20-<33$ weeks & $105(85)$ & $110(89)$ \\
\hline$\geq 33$ weeks & $6(5)$ & $5(4)$ \\
\hline
\end{tabular}

Percentages calculated according to treatment group.

$\mathrm{BMI}=$ body mass index, $\mathrm{Hb}=$ hemoglobin, $\mathrm{SD}=$ standard deviation. 


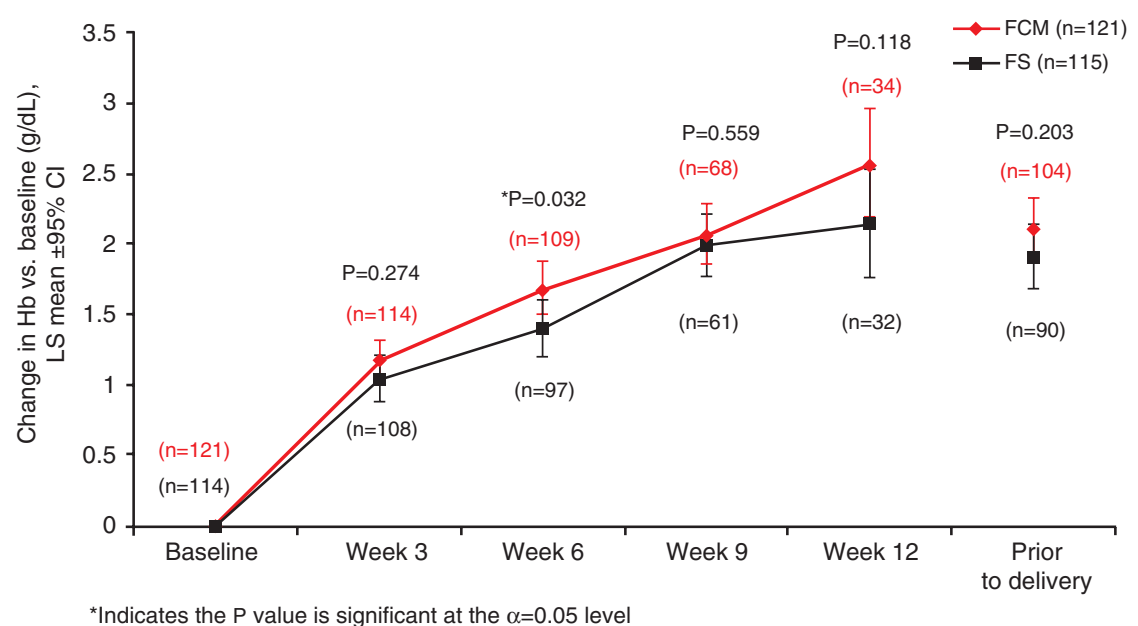

Figure 2: Change in hemoglobin levels.

$\mathrm{FCM}=$ ferric carboxymaltose, $\mathrm{FS}=$ ferrous sulfate, $\mathrm{Hb}=$ hemoglobin, $\mathrm{SD}=$ standard deviation.

significantly greater decreases with FCM treatment at weeks 6 and 9 (Figure 3C).

\section{Quality of life}

According to the SF-36 health survey, FCM treatment led to significant, clinically relevant improvements over FS in vitality prior to delivery (mean score change \pm standard deviation: FCM, 6.51 \pm 21.90 ; FS, 2.34 \pm 22.09 ; least-squares mean: 5.67 vs. -0.23 ; difference: $5.90,95 \%$ CI: 0.75, 11.04; $\mathrm{P}=0.025$ ) (Figure 4A). Significant improvements in social functioning were also evident prior to delivery following FCM vs. FS treatment (FCM, 3.03 \pm 23.61 ; FS, $-2.50 \pm 24.55$; least-squares mean: 3.28 vs. -2.49 ; difference: $5.77,95 \%$ CI: 0.01, 11.51; $\mathrm{P}=0.049$ ) (Figure 4B).

\section{Safety and tolerability}

The median (range) total dose administered was 1000 (21500) $\mathrm{mg}$ for FCM and 12,300 (200-20,500) mg for FS. One patient received only $2 \mathrm{mg}$ of FCM; administration was interrupted due to bronchospasm and the patient withdrew on day 6. One patient who received only $200 \mathrm{mg}$ of FS withdrew due to nausea on day 4.

The incidence of TEAEs was similar between the treatment arms: in the FCM group, 60 women (49\%) experienced 165 TEAEs; in the FS group, 50 women (40\%) experienced 105 TEAEs. The majority of events were mild in intensity (Table 3). Overall, the most common TEAEs were nausea (6\%), headache (5\%) and dyspepsia (4\%), and the most common TEAEs according to system organ class were "pregnancy, puerperium and perinatal conditions" in the FCM group [32 events in 26 women (21\%)] and "gastrointestinal disorders" in the FS group [42 events in 25 women $(20 \%)]$. The most common treatment-related TEAEs were headache with FCM [experienced by 4 women $(3 \%)$ ] and nausea with FS [in 6 women (5\%)], and markedly higher rates of gastrointestinal disorders were reported with FS treatment (in 16 women) compared with FCM treatment (3 women) (Table 4). Serious TEAEs occurred in 23 women treated with FCM (26 events) and in 10 women treated with FS (11 events); all were single events, except for "failed trial of labor", "fetal distress syndrome", "premature delivery", "premature rupture of membranes" and "threatened labor", each of which occurred in two women treated with FCM, and "premature labor", which occurred in three women treated with FS (pre-eclampsia was also reported to have occurred twice in one woman treated with FS). One serious TEAE, "bronchospasm", which was treatment related, led to discontinuation of FCM; this event was of moderate intensity and resolved on the same day after withdrawal of study treatment. Seven women discontinued treatment with FS because of gastrointestinal TEAEs $(n=5)$, syncope $(n=1)$ and rash $(n=1)$. No hypophosphatemia TEAEs were reported during this study. Eleven women (FCM, $n=10$; ferrous sulfate, $n=1$ ) recorded phosphate levels below the lower normal range threshold $[0.6 \mathrm{mmol} / \mathrm{L}(2 \mathrm{mg} / \mathrm{dL})]$; these decreases were largely observed at week 3 and recovered in all the women to within the normal range by the end of the study, indicating no clinical relevance of these findings.

\section{Newborn status}

Apgar scoring was similar between treatment groups. The overall mean Apgar score of the newborns at the first 


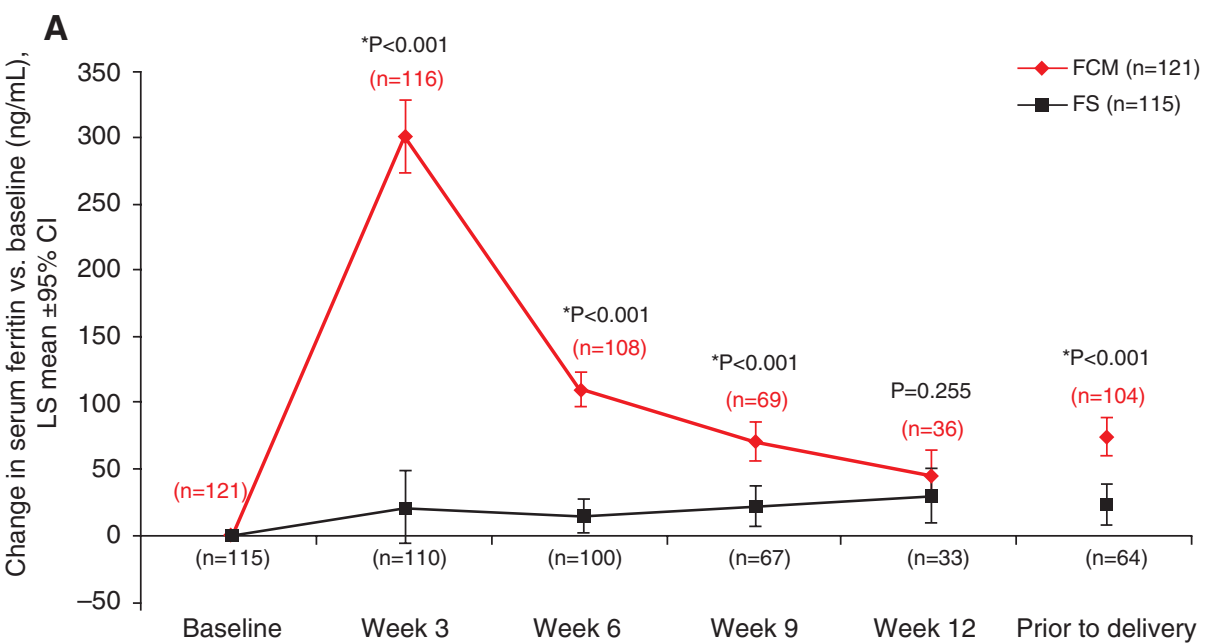

*Indicates the $P$ value is significant at the $\alpha=0.05$ level
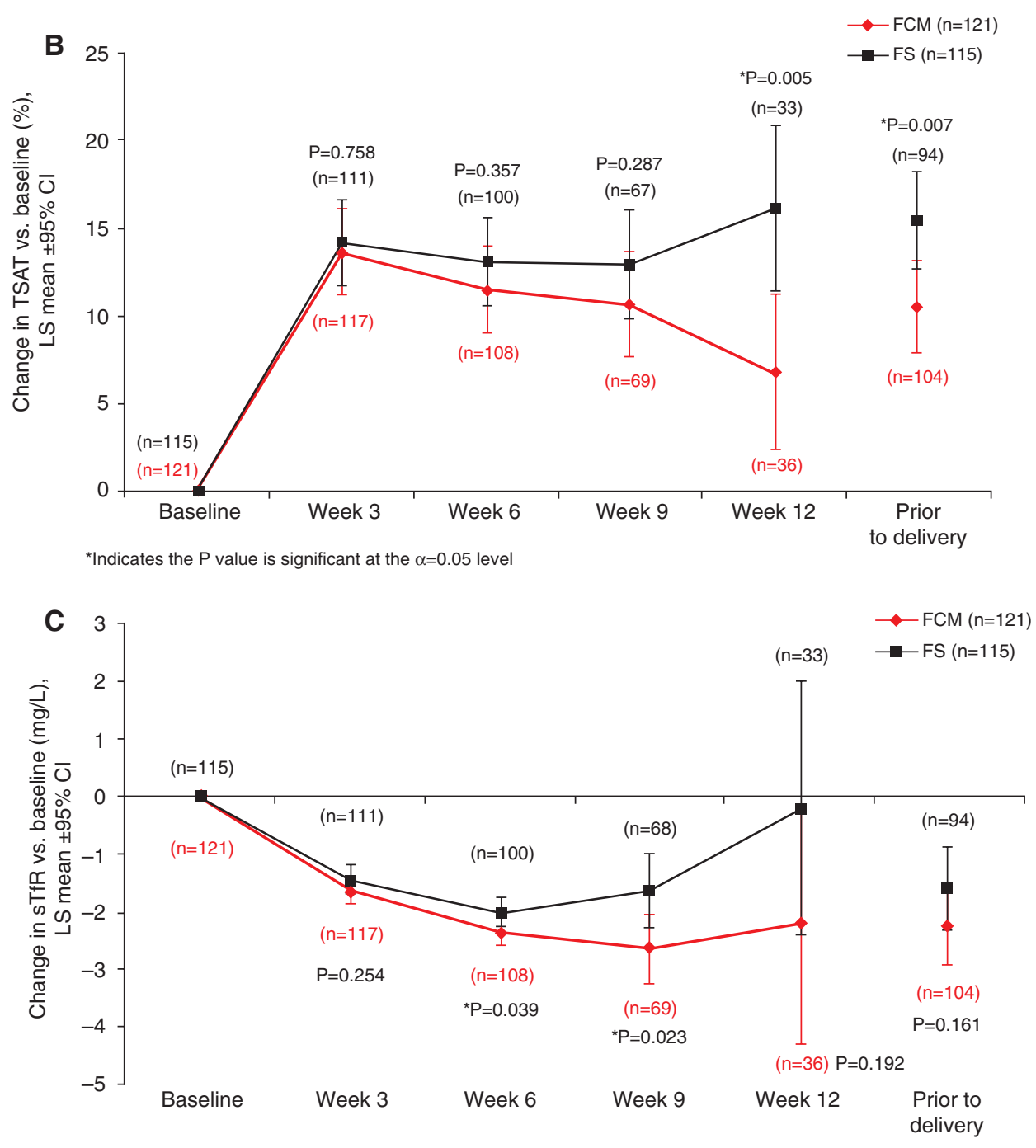

*Indicates the $P$ value is significant at the $\alpha=0.05$ level

Figure 3: Changes in other hematological parameters: (A) serum ferritin; (B) transferrin saturation; (C) soluble transferrin receptor. $\mathrm{FCM}=$ ferric carboxymaltose, $\mathrm{FS}=$ ferrous sulfate, $\mathrm{SD}=$ standard deviation, $\mathrm{SF}=$ serum ferritin, $\mathrm{sTfR}=$ soluble transferrin receptor, TSAT=transferrin saturation. 
A

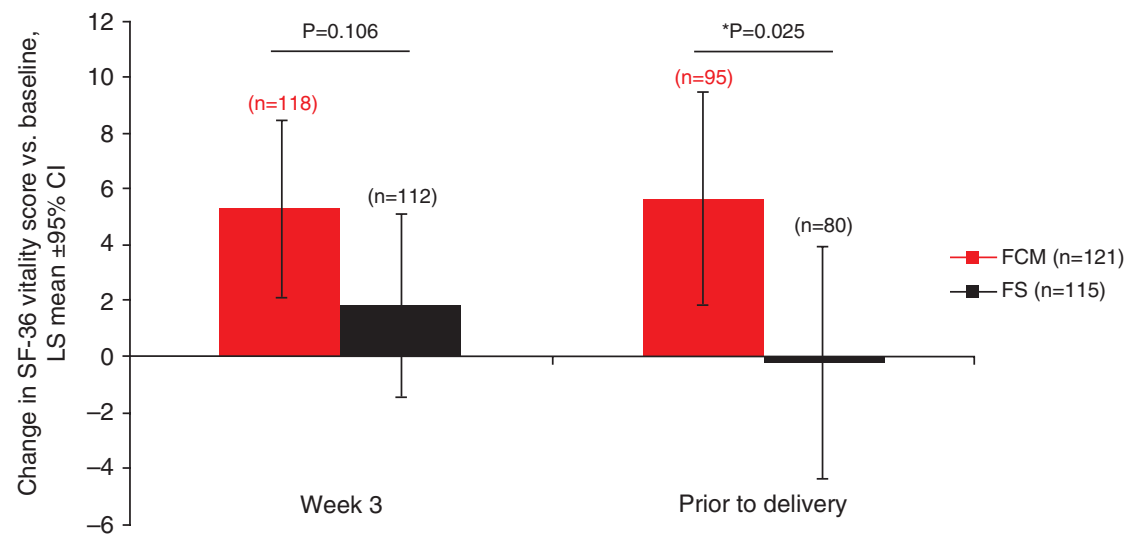

*Indicates the $P$ value is significant at the $\alpha=0.05$ level

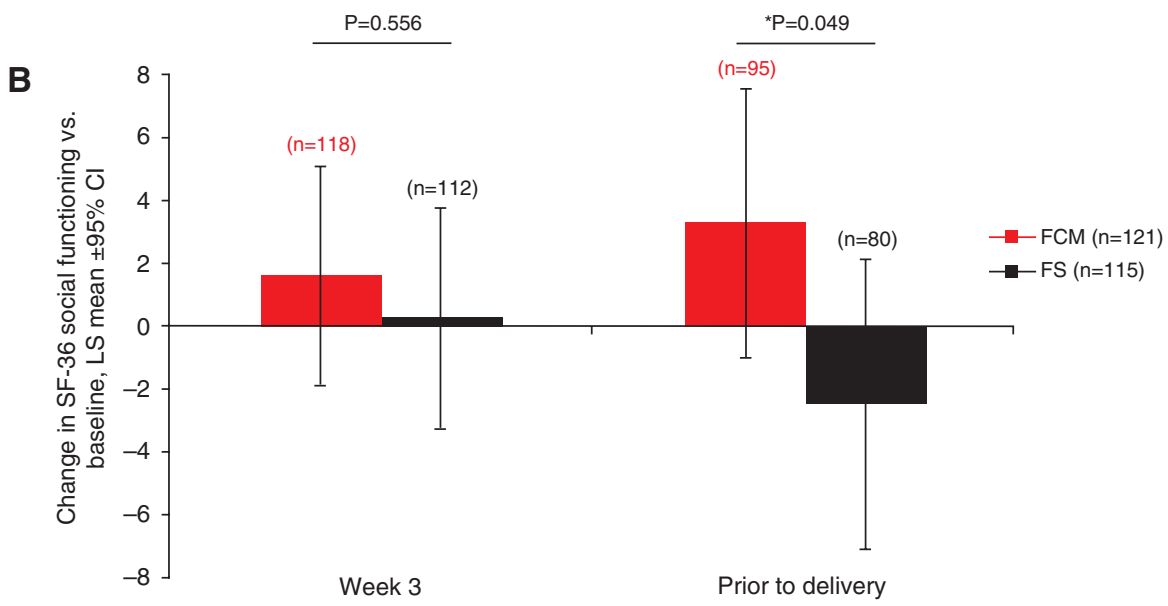

*Indicates the $P$ value is significant at the $\alpha=0.05$ level

Figure 4: Changes in SF-36 component scores: (A) vitality; (B) social functioning.

$\mathrm{FCM}=$ ferric carboxymaltose, $\mathrm{FS}=$ ferrous sulfate, $\mathrm{SF}-36=36$-item short-form health survey.

Table 3: Treatment-related TEAEs by severity.

\begin{tabular}{lrr}
\hline $\begin{array}{l}\text { Treatment-related } \\
\text { TEAE severity, number } \\
\text { of patients (\%) }\end{array}$ & $\begin{array}{r}\text { Ferric } \\
\text { carboxymaltose } \\
(\mathbf{n = 1 2 3 )}\end{array}$ & $\begin{array}{r}\text { Ferrous } \\
\text { sulfate } \\
(\mathbf{n}=124)\end{array}$ \\
\hline Total & $60(49)$ & $50(40)$ \\
Mild & $43(72)$ & $28(56)$ \\
Moderate & $17(28)$ & $20(40)$ \\
Severe & $0(0)$ & $2(4)$ \\
\hline
\end{tabular}

$\mathrm{TEAE}=$ treatment-emergent adverse event.

minute following birth was 8.3, increasing to 9.1 at $5 \mathrm{~min}$, with all achieving an Apgar score of 10 by $10 \mathrm{~min}$ after birth. Other newborn characteristics were also similar between treatments (Table 5). Independent of the mother's cord serum ferritin levels, all newborns were assessed to have normal serum ferritin levels.

\section{Discussion}

Our study demonstrates that IV FCM is effective and well tolerated in pregnant women with IDA during late-stage pregnancy and that women using this treatment give birth to healthy newborns. The increases in $\mathrm{Hb}$ levels were comparable between treatment arms in this study population. Although the primary efficacy endpoint was not met (FCM did not show superiority at week 3), this treatment did improve $\mathrm{Hb}$ levels to a significantly greater extent than oral iron by week $6(\mathrm{P}=0.032)$. Furthermore, we have demonstrated that FCM more rapidly and more effectively established normalized $\mathrm{Hb}$ levels $(\mathrm{Hb} \geq 11.0 \mathrm{~g} / \mathrm{dL}$ ) and was significantly more effective at replenishing iron stores than FS.

In preparation for childbirth, Hb levels are known to rise as pregnancy progresses and peak before delivery [5] 
Table 4: Treatment-related TEAEs (experienced by $\geq 2$ patients overall) by MedDRA primary system organ class and preferred term.

\begin{tabular}{lrr}
\hline Treatment-related TEAE, ${ }^{a}$ number of patients (\%) & $\begin{array}{r}\text { Ferric carboxymaltose } \\
(\mathbf{n = 1 2 3 )}\end{array}$ & $\begin{array}{r}\text { Ferrous sulfate } \\
(\mathbf{n = 1 2 4 )}\end{array}$ \\
\hline Total & $14(11)$ & $19(15)$ \\
Nervous system disorders & $7(6)$ & $1(1)$ \\
Headache & $4(3)$ & $0(0)$ \\
Dizziness & $3(2)$ & $0(0)$ \\
Dysgeusia & $2(2)$ & $0(0)$ \\
General disorders and administration-site conditions & $4(3)$ & $0(0)$ \\
Vascular disorders & $2(2)$ & $16(13)$ \\
Gastrointestinal disorders & $3(2)$ & $6(5)$ \\
Nausea & $2(2)$ & $2(2)$ \\
Vomiting & $0(0)$ & $3(2)$ \\
Constipation & $0(0)$ & $4(3)$ \\
Diarrhea & $0(0)$ & $5(4)$ \\
Abdominal pain upper & $0(0)$ & $3(2)$ \\
Dyspepsia & $0(0)$ & \\
\hline
\end{tabular}

aAccording to physician's assessment; a single patient could appear in multiple classes. Percentages calculated according to treatment group.

MedDRA=Medical Dictionary for Regulatory Activities (version 16.1), TEAE=treatment-emergent adverse event.

Table 5: Newborn characteristics (safety analysis set).

\begin{tabular}{lrr}
\hline & $\begin{array}{r}\text { Ferric carboxymaltose } \\
(\mathrm{n}=112)\end{array}$ & $\begin{array}{r}\text { Ferrous sulfate } \\
(\mathrm{n}=\mathbf{1 0 9})\end{array}$ \\
\hline Birth weight, mean (SD), kg & $3.4(0.5)$ & $3.4(0.5)$ \\
Birth length, mean (SD), cm & $50.8(2.6)$ & $50.7(3.0)$ \\
Birth weight/length ratio, mean (SD), kg/cm & $0.067(0.008)$ & $0.067(0.008)$ \\
Cord Hb level, mean (SD), g/dL & $14.8(1.9)$ & $14.6(1.7)$ \\
Cord hematocrit, mean (SD), ratio & $0.5(0.1)$ & $0.5(0.1)$ \\
Cord serum ferritin level, mean (SD), $\mathrm{ng} / \mathrm{mL}$ & $255.6(187.2)$ & $236.7(135.9)$ \\
\hline
\end{tabular}

$\mathrm{Hb}=$ hemoglobin, $\mathrm{SD}=$ standard deviation.

The loss of blood at childbirth can be considerable - it is the most common cause of postpartum anemia - therefore, sufficient iron stores are of particular importance during delivery and the postpartum period to overcome the recurrence of ID/IDA in the mother $[1,13,14]$ and newborn [1]. In this study, however, mean $\mathrm{Hb}$ levels appeared to be lower at the prior-to-delivery time point than at week 12 for both the FCM and the FS groups, inferring a decrease in Hb levels immediately prior to delivery. It is important to note that, because many women had already given birth by week 12 of this study, patient numbers for all hematological parameter assessments were lower at week 12 than at the prior-to-delivery time point. As a result, caution is warranted in interpreting week 12 data in the context of the other assessment time points. Furthermore, measurements prior to delivery were taken approximately 2 weeks before birth and therefore may not reflect the peak levels seen at delivery.
A conservative FCM treatment regimen was used for this study. This was based on dosage calculations according to the original label (with each single dose not to exceed $15 \mathrm{mg}$ iron per $\mathrm{kg}$ of body weight); more recently, a single higher dosage of FCM (20 mg iron per kg of body weight) has been approved [15]. Use of the lower dose of FCM in our study may have impacted on the outcomes and it must be considered that use of a higher dose, in accordance with the current label, may lead to greater efficacy. Our study is the first to compare FCM with FS in pregnant women; as such, confirmatory data are lacking in this particular patient population. However, FCM treatment in postpartum women has been comprehensively investigated and evidence from three large randomized controlled trials performed across Europe and North America support our findings: FCM was found to be at least as effective as FS at increasing $\mathrm{Hb}$ levels, and it showed superiority in providing more reliable anemia correction 
and in a shorter time [16-18]. FCM has also been compared with IV iron sucrose in pregnant women in a retrospective, observational study [19]. Here, the mean increase in $\mathrm{Hb}$ levels was numerically greater with FCM $(1.54 \mathrm{~g} / \mathrm{dL})$ than with iron sucrose $(1.17 \mathrm{~g} / \mathrm{dL})$, although this difference was not statistically significant. What was markedly different was the mean follow-up between the two groups (28.4 vs 41.2 days, respectively; $\mathrm{P}=0.01$ ), indicating that restoration of normal $\mathrm{Hb}$ levels was achieved much more quickly with FCM [19].

In addition to hematological effectiveness, a number of additional benefits of FCM over FS were demonstrated in our study. FCM had a dramatically reduced burden of treatment: comparable improvements in $\mathrm{Hb}$ levels were achieved with a 12-fold lower total dose and a 12-fold lower duration of exposure to FCM compared with FS. Outside the "compliance-friendly" environment of a clinical trial, a high burden of treatment can result in low compliance of patients with their medication, subsequently leading to worsening of disease and ultimately increased healthcare costs [20]. For some patients, a single dose of FCM may correct IDA with no repeated administration required, thereby providing a more convenient option than other iron treatments and potentially increasing compliance. In addition, treatment with FCM provided holistic benefit to these women in the later stages of their pregnancies. Our findings demonstrated that improvements immediately prior to delivery in the vitality of pregnant women treated with FCM were clinically relevant, and it is worth noting that these effects were evident using a generic quality-of-life assessment tool, SF-36, that was not specifically designed for application in anemic populations. It should be noted that study participants were not blinded to treatment and, therefore, the assessment of quality-of-life could have been influenced by subject bias. However, our findings are in accordance with those from a previous randomized, controlled trial in which FCM was found to significantly improve symptomatic fatigue in iron-deficient women [21]. Increased vitality can be of particular benefit in coping with the extreme physical stresses experienced by women during pregnancy and childbirth.

FCM was well tolerated in pregnant women during their second and third trimesters. The safety profile was consistent with what has been previously reported [16$18,22]$ and there were no unexpected safety concerns. As expected, treatment with FCM led to fewer gastrointestinal adverse events than FS; this considerable and clinically relevant lower burden of gastrointestinal complications is likely to be beneficial to the overall feeling of wellbeing and quality of life for women in the late stages of pregnancy. Gastrointestinal TEAEs led to discontinuation of FS in five women in our study and, as previously mentioned, such non-compliance increases the risk of IDA recurrence in these women. The frequencies of serious TEAEs experienced after FCM treatment in this trial (which included "failed trial of labor", "fetal distress syndrome", "premature delivery" and "premature rupture of membranes") are in line with those seen in a recent Cochrane review of iron supplementation in pregnant women (pregnant women receiving placebo or no treatment: preterm birth, 7.3\%; premature rupture of membranes, $12.2 \%$; pre-eclampsia, 2.2\%) [23]. Bronchospasm occurred in one woman treated with FCM that led to treatment withdrawal; this was considered to be a transient hypersensitivity reaction that resolved following discontinuation. Parenterally administered iron preparations can cause hypersensitivity reactions and bronchospasm is recognized as an adverse event that can occur rarely with ferric carboxymaltose treatment and is listed in the approved label [rare event $(\geq 1 / 10,000$ to $<1 / 1000$ of the treated population)] [24].

No complications associated with FCM treatment of the mothers were evident in the newborns. Cord serum ferritin levels were found to be numerically (although not statistically significantly) higher following FCM treatment, compared with oral iron treatment. Such cord serum ferritin levels reflect good iron reserves in the newborns for growth and development, thereby diminishing the risk of ID that can have important implications on infant morbidity and ongoing brain development and behavior [25]. Conversely, excessive levels of serum ferritin could indicate iron overload that can lead to serious complications for the newborn [25]. Such excessive levels were not observed in this study - all newborns of mothers treated with FCM had serum ferritin levels that fell within normal ranges $[26,27]$ and were completely healthy.

\section{Conclusions}

During the second and third trimesters, FCM has comparable efficacy to first-line oral iron treatment and is well tolerated in pregnant women with no complications evident in their newborns. In late-stage pregnancy, when time to delivery is a limiting step, administration of FCM may be a more appropriate option than oral iron for rapid and effective anemia correction. FCM is also a valuable alternative for pregnant women who lack a response to, are non-compliant with, or are intolerant of oral iron treatment, as well as those who have severe IDA. 
Acknowledgments: We would like to thank the following study investigators: Eduard Ailamazyan; Abdule-Kareem A. Al-Momen; Olus Api; Deniz Cemgil Arikan; Neriman Basak Baksu; Alexey Baranov; Nabeel Bondagji; Katarina Bremme; Irina Bushtureva; Yong-Kyoon Cho; Ala V. Dudareva; Sadiye Eren; Cuneyt Evrüke; Ildar Fatkullin; Bernd Froessler; Marina G. Gazazyan; Felix Grigoryan; Serkan Guçlu; Maria Günthner-Biller; Recep Has; Patrick Hohlfeld; Irene Hosli; Alexey B. Ilyin; Jong Kwan Jun; Lela Kavteladze; Ahm Kim; Young Ju Kim; Moon Young Kim; Christoph Konig; Olga Konstantinova; Mikhail Y. Korshunov; Vladislav Kovalev; Maritta Kuhnert; Wesam Ibrahim Kurdi; Ahmed Kurdi; Jeong Jae Lee; Young Lee; Keung-Young Lee; Boon Lim; Begona Martinez de Tajeda; Andreas Nonnenmacher; Olga B. Otdelnova; Irina Panova; Christian Polli; Bahauddin Sallout; Jong Chul Shin; Tae-Bok Song; Suzanna Sulaiman; Inger Sundstrom; Daniel Surbek; Dag-Vide Swensson; Nina Tatarova; Olga Tverskova; Klaus Vetter; Elle Wagström; Jan Wesström. Participating centers are listed in the Supplementary Appendix.

Conflict of interest: $\mathrm{CB}$ has provided medical consultancy to Vifor Pharma. NM and JD have no conflicts of interest to declare. AM and RB are employees of Vifor Pharma.

Funding: This study was sponsored by Vifor Pharma. Writing assistance was provided by Carly Hayes $\mathrm{PhD}$ from Mudskipper Business Ltd, funded by Vifor Pharma.

\section{References}

[1] Bothwell TH. Iron requirements in pregnancy and strategies to meet them. Am J Clin Nutr. 2000;72:257S-64S.

[2] Cantor AG, Bougatsos C, Dana T, Blazina I, McDonagh M. Routine iron supplementation and screening for iron deficiency anemia in pregnancy: a systematic review for the U.S. Preventive Services Task Force. Ann Intern Med. 2015;162:566-76.

[3] Milman N. Iron and pregnancy-a delicate balance. Ann Hematol. 2006;85:559-65.

[4] Camaschella C. Iron-deficiency anemia. N Engl J Med. 2015;372:1832-43.

[5] Milman N. Prepartum anaemia: prevention and treatment. Ann Hematol. 2008;87:949-59.

[6] Villar J, Merialdi M, Gulmezoglu AM, Abalos E, Carroli G, Kulier $R$, et al. Nutritional interventions during pregnancy for the prevention or treatment of maternal morbidity and preterm delivery: an overview of randomized controlled trials. J Nutr. 2003;133:1606S-25S.

[7] Scholl TO, Hediger ML. Anemia and iron-deficiency anemia: compilation of data on pregnancy outcome. Am J Clin Nutr. 1994;59:492S-500S.
[8] de Benoist B, McLean E, Egli I, Cogswell M, (eds). Worldwide prevalence of anaemia 1993-2005: WHO global database on anaemia. 2008. Available at: http://whqlibdoc.who.int/ publications/2008/9789241596657_eng.pdf.

[9] Breymann C, Honegger C, Holzgreve W, Surbek D. Diagnosis and treatment of iron-deficiency anaemia during pregnancy and postpartum. Arch Gynecol Obstet. 2010;282:577-80.

[10] Khalafallah AA, Dennis AE. Iron deficiency anaemia in pregnancy and postpartum: pathophysiology and effect of oral versus intravenous iron therapy. J Pregnancy. 2012;2012:630519.

[11] Pavord S, Myers B, Robinson S, Allard S, Strong J, Oppenheimer $C$. UK guidelines on the management of iron deficiency in pregnancy. Br J Haematol. 2012;156:588-600.

[12] Breymann C, Bian XM, Blanco-Capito LR, Chong C, Mahmud $G$, Rehman R. Expert recommendations for the diagnosis and treatment of iron-deficiency anemia during pregnancy and the postpartum period in the Asia-Pacific region. J Perinat Med. 2011;39:113-21.

[13] Milman N. Postpartum anemia I: definition, prevalence, causes, and consequences. Ann Hematol. 2011;90:1247-53.

[14] Milman N. Postpartum anemia II: prevention and treatment. Ann Hematol. 2012;91:143-54.

[15] Vifor Pharma Ltd. Ferinject $50 \mathrm{mg}$ iron $/ \mathrm{mL}$ solution for injection/infusion SmPC. Data on file. 2013.

[16] Breymann C, Gliga F, Bejenariu C, Strizhova N. Comparative efficacy and safety of intravenous ferric carboxymaltose in the treatment of postpartum iron deficiency anemia. Int J Gynecol Obstet. 2008;101:67-73.

[17] Seid MH, Derman RJ, Baker JB, Banach W, Goldberg C, Rogers $R$. Ferric carboxymaltose injection in the treatment of postpartum iron deficiency anemia: a randomized controlled clinical trial. Am J Obstet Gynecol. 2008;199:435-7.

[18] Van Wyck DB, Martens MG, Seid MH, Baker JB, Mangione A. Intravenous ferric carboxymaltose compared with oral iron in the treatment of postpartum anemia: a randomized controlled trial. Obstet Gynecol. 2007;110:267-78.

[19] Christoph P, Schuller C, Studer H, Irion O, De Tejada BM, Surbek $D$. Intravenous iron treatment in pregnancy: comparison of high-dose ferric carboxymaltose vs. iron sucrose. J Perinat Med. 2012;40:469-74.

[20] Osterberg L, Blaschke T. Adherence to medication. N Engl J Med. 2005;353:487-97.

[21] Favrat B, Balck K, Breymann C, Hedenus M, Keller T, Mezzacasa A, et al. Evaluation of a single dose of ferric carboxymaltose in fatigued, iron-deficient women - PREFER a randomized, placebo-controlled study. PLoS One. 2014;9:e94217.

[22] Froessler B, Collingwood J, Hodyl NA, Dekker G. Intravenous ferric carboxymaltose for anaemia in pregnancy. BMC Pregnancy Childbirth. 2014;14:115.

[23] Pena-Rosas JP, De-Regil LM, Garcia-Casal MN, Dowswell T. Daily oral iron supplementation during pregnancy. Cochrane Database Syst Rev. 2015;7:CD004736.

[24] electronic Medicines Compendium (eMC). Ferinject (ferric carboxymaltose). 2013. Available at: http://www.medicines.org. uk/EMC/medicine/24167/SPC/Ferinject+\%28ferric+carboxym altose $\% 29 /$.

[25] Rao R, Georgieff MK. Iron in fetal and neonatal nutrition. Semin Fetal Neonatal Med. 2007;12:54-63. 
[26] Siddappa AM, Rao R, Long JD, Widness JA, Georgieff MK. The assessment of newborn iron stores at birth: a review of the literature and standards for ferritin concentrations. Neonatology. 2007;92:73-82.

[27] Wiedemann G, Jonetz-Mentzel L. Establishment of reference ranges for ferritin in neonates, infants, children and adolescents. Eur J Clin Chem Clin Biochem. 1993;31:453-7.
Article note: Previous presentations: Oral presentation at FIGO 2015, with abstract published in the International Journal of Gynecology \& Obstetrics.

Supplemental Material: The online version of this article (DOI: 10.1515/.jpm-2016-0050) offers supplementary material, available to authorized users. 